\title{
HUBUNGAN PENGETAHUAN DENGAN SIKAP IBU TERHADAP BALITA BERPENYAKIT INFEKSI SALURAN PERNAPASAN AKUT (ISPA) DI PUSKESMAS TINGGEDE
}

\author{
Riskayati \\ Yayasan Pendidikan Cendrawasih Akademi Kebidanan Palu
}

\begin{abstract}
ABSTRAK
Latar Belakang : Kejadian penyakit ISPA (Infeksi Saluran Pernapasan Akut) pada balita masih cukup tinggi di Sulawesi Tengah.Tercatat sebanyak 138.740 balita yang menjadi penderita ISPA di Sulawesi Tengah pada tahun 2013. Berdasarkan data yang didapatkan dari Puskesmas Tinggede, dari 874 balita terdapat 428 balita yang terkena ISPA. Tujuan penelitian : untuk mengetahui hubungan pengetahuan dengan sikap ibu terhadapbalitaberpenyakit ISPA.Jumlah sampel pada penelitian ini adalah sebesar 90 ibu dengan balita yang berobat ke puskesmas Tinggede. Metode Penelitian : penelitian ini merupakan survei analitik dengan menggunakan kuesioner. Hasil penelitian : menunjukkan dari 90 responden, responden yang memiliki pengetahuan baik berjumlah 69 responden yang tediri dari 66 responden $(73,3 \%)$ bersikap baik, dan yang memiliki sikap kurang baik berjumlah 3 responden $(3,3 \%)$. Sedangkan responden berpengetahuan kurang baik berjumlah 21 responden yang terdiri dari 20 responden $(22,2 \%)$ bersikap baik dan yang memiliki sikap kurang baik 1 responden $(1,1 \%)$. Dari hasil analisa bivariat dilakukan uji chi square didapatkan p.value 0,936 > 0,05. Kesimpulan : tidak ada hubungan yang signifikan antara pengetahuan terhadap sikap ibu mempunyai anak balita dengan kejadian penyakit ISPA di Puskesmas Tinggede.
\end{abstract}

Kata kunci : Pengetahuan, Sikap, Penyakit Infeksi Saluran Pernapasan Akut (ISPA)

\section{ABSTRACT}

Acute Respiratory Tract Infection (ARTI) in childhood is still high in number in Central Sulawesi. Reported 138.740 child had ARTI in Central Sulawesi in 2013. According to data of Puskesmas Tinggede from 874 child there were 428 child which acquire ARTI. The aim of this study was to find the correlation of mother's knowledge with her attitude toward their child with ARTI. Number of samples in this study was 90 mother whose child was treated in Puskesmas Tinggede. This study was analytic survey kind of study which using questionnaire as research tool. Study result present from 90 respondents, those with good knowledge were 69 respondents including $66(73,3 \%)$ with good attitude and $3(3,3 \%)$ with bad attitude. Respondents with bad knowledge were 21 including $20(22,2 \%)$ with good attitude and $1(1,1 \%)$ with bad attitude. Analysis of correlation using chi square resulted $p$ value $0,936>0,05$. This result concluded if there was no significant correlation between mother's knowledge with her attitude toward their child with ARTI in Puskesmas Tinggede.

Keywords: Knowledge, Attitude, Acute Respiratory Tract Infection (ARTI) 
PENDAHULUAN

ISPA adalah penyakit yang menyerang salah satu bagian dan atau lebih dari saluran napas mulai dari hidung (saluran atas) hingga alveoli (saluran bawah) termasuk jaringan adneksanya, seperti sinus, rongga telinga tengah dan pleura.ISPA umumnya berlangsung selama 14 hari, termasuk infeksi saluran napas bagian atas adalah batu pilek biasa, sakit telinga, radang tenggorokan, influena, bronchitis dan juga sinusitis. Sedangkan infeksi yang menyerang bagian bawah saluran napas seperti paru itu salah satunya adalah pneumonia (Syafrudin, AD and Delmaifanis, 2011).

Berdasarkan World Health Organization (WHO) insiden infeksi saluran pernapasan akut (ISPA) di Negara berkembang angka kematian balita diatas 40 per 1000 kelahiran hidup adalah $15 \%$ - $20 \%$ pertahun pada golongan usia balita. Menurut WHO kurang lebih 13 juta anak balita di dunia meninggal setiap tahun dan sebagian besar kematian tersebut terdapat di Negara berkembang, dimana pneumonia merupakan salah satu penyebab utama dengan membunuh kurang lebih 4 juta anak balita setiap tahun (Susanto, Prasenohadi and Yunus, 2010).

Sesuai dengan data Dinas Kesehatan Provinsi Sulawesi Tengah dari bulan Januari sampai dengan Desember tahun 2013 tercatat jumlah penduduk balita sebanyak 274.155 dan yang menderita ISPA sebanyak 138.740 balita(Dinas Kesehatan Provinsi Sulawesi Tengah, 2014a). Pada tahun 2014 dari bulan Januari sampai dengan Agustus penduduk balita sebanyak 276.530 balita dan yang menderita ISPA sebanyak 82.823 balita (Dinas Kesehatan Provinsi Sulawesi Tengah, 2014b).

Berdasarkan data dari Dinas Kesehatan Kota Palu tahun 2014 jumlah balita di kota Palu sebanyak 34.534 balita. Jumlah balita penderita Infeksi Saluran Pernapasan Akut (ISPA) adalah 1530 balita (Dinas Kesehatan Kota Palu,
2014).

Data yang diperoleh dari Dinas Kesehatan Kabupaten Sigi tahun 2013 jumlah balita sebanyak 22.006 balita dan penderita ISPA sebanyak16.660 balita (Dinas Kesehatan Kabupaten Sigi, 2014a). Sedangkan pada tahun 2014 dari bulan Januari sampai bulan September jumlah balita sebanyak 22.006 dan penderita ISPA sebanyak 9.932 balita (Dinas Kesehatan Kabupaten Sigi, 2014b).

Jumlah keseluruhan balita yang diperoleh dari puskesmas Tinggede tahun 2014 dari bulan Januari sampai dengan Oktober adalah 874 balita. Jumlah penderita ISPA di puskesmas Tinggede bulan Januari sampai dengan Oktober 2014 adalah sebanyak 428 orang. Jumlah ini menempatkan ISPA menjadi penyakit nomor satu terbanyak di lingkungan kerja puskesmas Tinggede (Puskesmas Tinggede, 2014).

Pengetahuan adalah kesan di dalam pikiran manusia sebagai hasil penggunaan

pancainderanya.Pengetahuan adalah segala apa yang diketahui berdasarkan pengalaman yang didapatkan oleh setiap manusia. Proses pengetahuan melibatkan tiga aspek, yaitu proses mendapatkan informasi, proses transformasi, dan proses evaluasi. Informasi baru yang didapat merupakan pengganti pengetahuan yang telah diperoleh sebelumnya atau merupakan penyempurnaan informasi sebelumnya. Proses transformasi adalah proses manipulasi pengetahuan agar sesuai dengan tugas-tugas baru. Proses evaluasi dilakukan dengan memeriksa kembali apakah cara mengolah informasi telahmemadai. Sehingga, perilaku yang didasari oleh pengetahuan akan lebih langgeng daripada perilaku yang tidak didasari oleh pengetahuan (Mubarak, 2011).

Sikap adalah perasaan, pikiran, dan kecenderungan seseorang yang kurang lebih bersifat permanen mengenai aspekaspek tertentu dalam lingkungannya. 
Sikap merupakan kecondongan evaluative terhadap suatu stimulus atau objek. Oleh karena itu, sikap menunjukkan kesetujuan atau ketidaksetujuan, suka atau tidak suka seseorang terhadap sesuatu. Sikap mempunyai tiga komponen utama yaitu kepercayaan/ keyakinan (ide dan konsep), kehidupan emosional atau evaluasi emosional terhadap suatu objek, dan kecenderungan untuk bertindak (tren to behave). Ketiga komponen tersebut secara bersama-sama membentuk sikap yang utuh (total attitude) (Mubarak, 2011).

Penelitian bertujuan untuk mengetahui hubungan pengetahuan terhadap sikap ibu yang mempunyai anak balita dengan penyakit ISPA di Puskesmas Tinggede Kabupaten Sigi Provinsi Sulawesi Tengah.

\section{METODE PENELITIAN}

Jenis penelitian ini adalah metode survei analitik dengan rancangan penelitian cross sectional. Penelitian ini dilakukan di Puskesmas Tinggede Kabupaten Sigi Provinsi Sulawesi Tengah pada tanggal 19 Maret - 13 Juni tahun 2015.

Populasi dalam penelitian ini adalah seluruh ibu yang mempunyai anak balita yang datang berobat pada saat penelitian di Puskesmas Tinggede dengan total Populasi 874 ibu mempunyai anakbalita. Jumlah sampel penelitian ini adalah 90 ibu yang mempunyai anak balita. Teknik pengambilan sampel dalam penelitian ini adalah dengan menggunakan metode accidental sampling.

Variabel independen pada penelitian ini adalah pengetahuan ibu yang mempunyai anak balita.Variabel ini diukur menggunakan kuesioner yang berisi segala sesuatu yang diketahui dan dipahami ibu tentang penyakitISPA. Pengetahuan dianggap baik jika skor jawaban responden $\geq$ nilai skor10; sedangkan kurang baik jika skor jawaban responden < nilai skor 10 . Variabel dependen pada penelitian ini adalah sikap ibu dengan kejadian penyakit ISPA. Variabel ini diukur menggunakan kuesioner yang menanyakan reaksi ibu yang mempunyai anak balita dalam menerima, merespon tentang penyakitISPA. Sikap ibu dianggap baik jika skor jawaban responden $\geq$ nilai skor 15; sedangkan kurang baik jika skor jawaban responden < nilai skor 15 .

Untuk melihat kemaknaan hubungan antara variabel independen dengan variable denpenden dengan menggunakan uji chi square yang dapat dihitung dengan menggunakan software SPSS dan didukung oleh Microsoft excel 2007 dengan tingkat kepercayaan 95\%.Terdapat hubungan antara kedua variabel apabila $x^{2}$ hitung $>x^{2}$ tabel $a$ (derajat bebas tertentu).Tidak terdapat hubungan antara kedua variabelapabila $x^{2}$ hitung $<x^{2}$ tabel $\alpha$ (derajat bebas tertentu).

\section{HASIL PENELITIAN}

\section{Pengetahuan}

Berdasarkan Tabel 1 bahwa dari 90 responden, responden yang mempunyai pengetahuan baik tentang penyakit ISPA sebanyak 69 responden $(76,7 \%)$ dan responden yang memiliki pengetahuan kurang baik tentang penyakit ISPA sebanyak 21 responden (22,3\%). Secara kumulatif pengetahuan responden tentang penyakit ISPA masuk dalam kategori baik.

2. Sikap

Berdasarkan Tabel 2 bahwa dari 90 responden, responden yang mempunyai sikap baik terhadap penyakit ISPA sebanyak 86 responden $(95,6 \%)$ dan responden yang memiliki sikap kurang baik terhadap penyakit ISPA sebanyak 4 responden $(4,4 \%)$. Secara kumulatif sikap responden pada penyakit ISPA masuk dalam kategori baik.

3. Hasil Analisis Bivariat 
BerdasarkanTabel 3 bahwa responden yang memiliki pengetahuan baik berjumlah 69 responden yang tediri dari 66 responden $(73,3 \%)$ bersikap baik, dan yang memiliki sikap kurang baik berjumlah 3 responden (3,3\%). Sedangkan responden berpengetahuan kurang baik berjumlah 21 responden yang terdiri dari 20 responden $(22,2 \%)$ bersikap baik dan yang memiliki sikap kurang baik 1 responden $(1,1 \%)$.

Tabel 1

Distribusi frekuensi pengetahuan responden tentang penyakit ISPA di Puskesmas Tinggede

\begin{tabular}{ccc}
\hline Pengetahuan & Frekuensi & Persent \\
$(1)$ & $(2)$ & $(3)$ \\
\hline Baik & 69 & 76,7 \\
Kurang Baik & 21 & 22,3 \\
\hline Total & 90 & 100 \\
\hline
\end{tabular}

Tabel 2

Distribusi frekuensi sikap responden tentang penyakit ISPA di Puskesmas Tinggede

\begin{tabular}{ccc}
\hline Sikap & Frekuensi & Persent \\
$(1)$ & $(2)$ & $(3)$ \\
\hline Baik & 86 & 95,6 \\
Kurang Baik & 4 & 4,4 \\
\hline Total & 90 & 100 \\
\hline
\end{tabular}

Tabel 3

Presentase sikap responden menurut pengetahuan dengan kejadian penyakit ISPA di Puskesmas Tinggede Palu

\begin{tabular}{|c|c|c|c|c|c|c|}
\hline \multirow{3}{*}{ No. } & \multirow{3}{*}{ Pengetahuan } & \multicolumn{2}{|c|}{ Sikap } & \multirow{2}{*}{ Total } & \multicolumn{2}{|c|}{ Analisis Bivariat } \\
\hline & & Baik & Kurang Baik & & \multirow{2}{*}{$p$ value } & \multirow[b]{2}{*}{ IK 95\% } \\
\hline & & $f(\%)$ & $f(\%)$ & $\mathrm{n}(\%)$ & & \\
\hline 1. & Baik & $66(73,3)$ & $3(3,3)$ & $69(76,7)$ & \multirow{3}{*}{0,936} & \multirow{3}{*}{0,05} \\
\hline 2. & Kurang Baik & $20(22,2)$ & $1(1,1)$ & $21(23,3)$ & & \\
\hline & Jumlah & $86(95,56)$ & $4(4,4)$ & 90 (100) & & \\
\hline
\end{tabular}

$\mathrm{F}=$ frekuensi, $\%=$ persentase, $\mathrm{n}=$ jumlah, $\mathrm{IK}=$ interval kepercayaan (convidence interval)

Hasil analisis dengan uji chi-square didapatkan hasil hitung yaitu p.value 0,936 . Karena nilai p.value 0,936 $>0,05$ maka $\mathrm{HO}$ diterima dan $\mathrm{Ha}$ ditolak artinya tidak ada hubungan yang signifikan antara pengetahuan dan sikap dengan kejadian penyakit ISPA di Puskesmas Tinggede.

\section{PEMBAHASAN}

1. Pengetahuan

Pengetahuan merupakan hasil mengingat suatu hal, termasuk 
mengingat kembali kejadian yang pernah dialami baik secara sengaja maupun tidak disengaja dan ini terjadi setelah orang melakukan kontak atau pengamatan terhadap suatui objek tertentu. Perilaku yang didasari oleh pengetahuan akan lebih langgeng dari pada perilaku yang tidak didasari oleh pengetahuan (Misalnya perilaku karena paksaan atau adanya aturan wajib) (Mubarak, 2011).

Berdasarkan hasil penelitian yang diperoleh tentang pengetahuan ibu yang mempunyai balita di Puskesmas Tinggede dari 90 responden 69 orang $(76,7 \%)$ mempunyai pengetahuan baik. Pengetahuan ibu balita yang baik tentang penyakit ISPA dipengaruhi oleh pengalaman dan minat ibu untuk mencari informasi tentang penyakit ISPA, serta mengikuti dan mengerti tentang penyuluhan penyakit ISPA yang diberikan oleh tenaga kesehatan. Selain itu pengetahuan ibu balita yang baik disebabkan karenabanyaknya responden yang memiliki pendidikan menengah keatas serta usia $\geq 25$ tahun. Tingkat pendidikan dan usia turut pula menentukan mudah tidaknya seseorang menyerap dan memahami informasi yang mereka peroleh. Pada umumnya semakin dewasa seseorang maka pemikiranya semakin matang serta semakin banyak pengalaman yang didapatkan.

Pengetahuan responden yang kurang baik berjumlah 21 orang $(23,3 \%)$. Hal ini dapat dilihat dari hasil jawaban yang diberikan oleh responden pada kuesioner, sebagian kecil masih ada yang belum memahami dan mengerti tentang apa itu penyakit ISPA, dari pengetahuan yang kurang baik, responden sering tidak merespon atau mendengarkan apa yang disampaikan oleh tenaga kesehatan, sehingga responden kurang memahami penyebab atau gejala dari penyakit ISPA untukbalitanya.

Dalam bidang kesehatan masyarakat khususnya pendidikan kesehatan, mempelajari perilaku adalah sangat penting.Karena pendidikan kesehatan sebagai bagian dari kesehatan masyarakat, berfungsi sebagai media sarana atau menyediakan kondisi sosio-psikologis sedemikian rupa sehingga individu atau masyarakat berperilaku melakukan tindakan sesuai dengan norma-norma hidup sehat. Dengan kata lain pendidikan kesehatan bertujuan untuk merubah perilaku individu atau masyarakat sehingga sesuai dengan norma hidup sehat.

Hal ini sejalan dengan teori yang dikemukakan Mubarak (2011) Padadasarnya pengetahuan akan terus bertambah dan bervariatif sesuai dengan prose spengalaman manusia yang dialami. Menurut Brunner, prosespengetahuan tersebut melibatkan tiga aspek, yaitu proses mendapatkan informasi, proses transformasi, dan proses evaluasi. Informasi baru yang didapat merupakan pengganti pengetahuan yang telah diperoleh sebelumnya atau merupakan penyempurnaan informasi sebelumnya. Proses transformasi adalah proses manipulasi pengetahuan agar sesuai dengan tugas-tugas baru. Proses evaluasi dilakukan dengan memeriksa kembali apakah cara mengolah informasi telah memadai.

\section{Sikap}

Sikap adalah perasaan, pikiran, dan kecenderungan seseorang yang kurang lebih bersifat permanen mengenai aspek-aspek tertentu dalam lingkungannya. Sikap merupakan kecondongan evaluative terhadap suatu stimulus atau objek tersebut. Ini berarti sikap menunjukkan kesetujuan atau ketidaksetujuan, suka atau tidak suka seseorang terhadap sesuatu(Mubarak, 2011).

Berdasarkan hasil penelitian yang sudah dilakukan didapatkan bahwa sikap responden pada kejadian penyakit ISPA paling banyak memiliki sikap baik yaitu dari 90 responden ada 
86 orang (95,6\%) mempunyai sikap baik. Hal ini ditunjukkan oleh kemauan responden untuk mencari informasi di fasilitas kesehatan serta kemampuan responden menjawab dengan baik pada pernyataan tentang penyakit ISPA. Hal ini disebabkan banyaknya responden yang memiliki tingkat pendidikan menengah keatas serta usia $\geq 25$ tahun, karena semakin dewasa individu maka semakin baik pula individu tersebut menyikapi keadaan yang ada. Selain itu hal ini juga disebabkankarena responden mau mendengarkan penyuluhan dan melaksanakan apa yang sudah disampaikan oleh tenaga kesehatan. Sebaliknya responden yang mempunyai sikap kurang bailk terhadap penyakit ISPA yaitu 4 orang $(4,4 \%)$. Hal ini disebabkan karena kurangnya kesadaran dan respon ibu tentang penyakit ISPA, kurangnya motivasi ibu balita untuk mencari informasi atau orang yang berada disekitarnya kurang memberikan informasi.

Hal ini sejalan dengan teori yang dikemukakan Mubarak (2011). Sikap dalam kehidupan sehari-hari merupakan reaksi yang bersifat emosional terhadap stimulus sosial.Sikap bukan suatu tindakan atau aktivitas melainkan predisposisi tindakan atau perilaku.

\section{Hubungan Pengetahuan Terhadap \\ Sikap Dengan Kejadian Penyakit \\ ISPA di Puskesmas Tinggede Palu}

Berdasarkan hasil penelitian menunjukkan bahwa responden yang memiliki pengetahuan baik berjumlah 69 responden yang tediri dari 66 responden $(73,3 \%)$ bersikap baik, dan yang memiliki sikap kurang baik berjumlah 3 responden (3,3\%). Sedangkan responden berpengetahuan kurang baik berjumlah 21 responden yang terdiri dari 20 responden $(22,2 \%)$ bersikap baik dan yang memiliki sikap kurang baik 1 responden (1,1\%).

Hasil analisis dengan uji chi-square didapatkan hasil hitung yaitu p.value
0,936 . Karena nilai p.value $0,936>0,05$ maka $\mathrm{HO}$ diterima dan $\mathrm{Ha}$ ditolak artinya tidak ada hubungan yang signifikan antara pengetahuan dan sikap dengan kejadian penyakit ISPA di Puskesmas Tinggede. Hal ini dapatdilihat dari hasil pengisian kuesioner dimana responden yang memiliki pengetahuan kurang baik lebih banyak dibandingkan dengan responden yang memiliki sikap kurang baik.

Pengetahuan responden yang kurang baik tetapi sebagian memiliki sikap baik, hal ini dikarenakan pengalaman ibu dalam bertindak apabila anaknya sakit selain itu rasa tanggung jawab dan rasa sayang orang tua terhadap anaknya, sehingga apabila orang tua terutama ibu mendapatkan anaknya kurang sehat pasti akan khawatir dengan kesehatan anaknya. Oleh karena itu, ibu pasti langsung memeriksakan anaknya ke tenaga kesehatan apabila mendapatkan tanda-tanda dan gejala sakit / ISPA pada anaknya.

Kartini menyatakan bahwa semakin baik pengetahuan dan sikap ibu terhadap kesehatan seorang anak, maka akan mengurangi resiko terjadinya penyakit ISPA pada balita, sebaliknya apabila semakin buruk pengetahuan dan sikap ibu terhadap kesehatan anaknya, maka resiko terjadinya ISPA pada balita akan semakin tinggi.

Hal ini sejalan dengan teori yang dikemukakan Mubarak (2011) Pengetahuan adalah kesan di dalam pikiran manusia sebagai hasil penggunaan pancainderanya. Pengetahuan sangat berbeda dengan kepercayaan, takhayul, dan penerangan-penerangan yang keliru. Pengetahuan adalah segala apa yang diketahui berdasarkan pengalaman yang didapatkan oleh setiap manusia.

\section{KESIMPULAN}

Berdasarkan hasil penelitian maka 


\begin{abstract}
diperoleh pengetahuan dan sikap responden secara kumulatif baik.Responden yang memilki pengetahuan kurang baik tidak semuanya memiliki sikap yang kurang baik maka dapat diambil kesimpulan bahwa tidak ada hubungan yang signifikan antara pengetahuan dan sikap ibu yang mempunyai anak balita dengan kejadian penyakit Infeksi Saluran Pernapasan Akut (ISPA) di Puskesmas Tinggede.
\end{abstract}

\section{SARAN \\ Bagi petugas kesehatan di Puskesmas Tinggede agar lebih meningkatkan pelayanan kesehatan kepada masyarakat serta memberi penyuluhan kepada masyarakat khususnya ibu-ibu yang mempunyai anak balita tentang penyakit ISPA.}

DAFTAR PUSTAKA

Dinas Kesehatan Kabupaten Sigi (2014a) Rekap Laporan Pengendali ISPA Kabupaten Sigi 2013. Sigi.

Dinas Kesehatan Kabupaten Sigi (2014b) Rekap Laporan
Pengendali ISPA Kabupaten Sigi Januari-September 2014. Sigi.

Dinas Kesehatan Kota Palu (2014) Rekap Laporan Pengendali ISPA Kota Palu 2014. Palu.

Dinas Kesehatan Provinsi Sulawesi Tengah (2014a) Rekap Laporan Pengendali ISPA Propinsi Sulawesi Tengah 2013. Palu.

Dinas Kesehatan Provinsi Sulawesi Tengah (2014b) Rekap Laporan Pengendali ISPA Propinsi Sulawesi Tengah JanuariAgustus 2014. Palu.

Mubarak, W. I. (2011) Promosi Kesehatan Untu Kebidanan. Jakarta: Salemba Medika.

Puskesmas Tinggede (2014) Laporan Bulanan Program P2 ISPA Tinggede. Tinggede.

Susanto, A., Prasenohadi and Yunus, F. (2010) The Year of the Lung.

Syafrudin, AD, D. and Delmaifanis (2011) 'Himpunan Penyuluhan Kesehatan Pada Remaja, Keluarga,Lansia Dan Masyarakat', Trans Info Media. 